779 EFFECTS OF MATERNAL ALCOHOL INTOXICATION ON FETAL MYOCARDIAL FUNCTION. Harry Bard, Jean-Claude Fouron, Josée Lafond. Univ. of Montreal,

Ste-Justine, Department of Pediatrics, Montreal, Canada. could effect fetal myocardial function, studies were carried on 5 chronically catheterized fetal sheep during maternal alcohol infusion. Absolute ethyl alcohol $(0.8 \mathrm{mI} / \mathrm{kg})$ was administered to the mother over a 10 minute period via the jugular vein. to the mother over a 10 minute period via the Jugular vein.
These infusions were repeated every 30 minutes during 3 hours and peak maternal and fetal blood concentrations of $200 \mathrm{mg} / 100$ $\mathrm{ml}$ of alcohol were reached. The fetal $\mathrm{PO}_{2}$ increased from 19.47 \pm 1.71 to $22.85 \pm 2.38$ Torr $(\mathrm{p}<0.05)$ and the $\mathrm{PCO}_{2}$ decreased from $43.15 \pm 3.75$ to $41.45 \pm 4.07$ Torr $(p<0.05)$, without affecting pH. The systolic time Intervals of the fetal heart showed a rapid and prolonged modification. The pre-ejection period increased from $58 \pm 8$ to $66 \pm 4 \mathrm{msec}(p<0.05)$ during the infusion and remained elevated until the end of the experithe Infusion and rematned elevated until the end increase in the ments (12 hours). This change was due to an increase fection isometric contraction period. The ratio of the pre-ejection
period over the ejection time was also increased. A rise in fetal systolic and diastolic pressures was observed at around 2 hours after the start of the alcohol infusion, and lasted 4 hours. This study demonstrates that an episode of maternal alcohol intoxication causes a rapid depression of fetal myocardial contractility which is maintained several hours after cessation of alcohol ingestion. The depressive effect of maternal alcohol on the fetal myocardium could be a factor of risk for the fetus.

RESPONSE TO PROSTACYCLIN (PGI2) PREDICTS RESPONSE TO 80 SUBSEQUENT VASODICATOR THERAPY IN PRIMARY PULMONARY HYPERTENSION (PPH). Robyn J. Barst, Walker A. Long, S. Alex Stalcup. Dept. of Pediatrics, Columbia Univ. College of Physicians \& Surgeons, New York, NY and Burroughs-Wellcome Co. Research Triangle, NC.

Nine patients with PPH (9 mos to 23 yrs) were studied with PGI2 to assess pulmonary vasoreactivity. A positive response to PGI2 was defined as a $20 \%$ or greater decrease in mean pulmonary arterial pressure ( $(\overline{P A P})$ with no change or an increase in cardiac index (C.I.).

Positive Response

$(\mathrm{n}=5 ; 9$ mos to 13 yrs)

Control $\mathrm{PGI}_{2}$

$\overrightarrow{\mathrm{PAP}}$ (mmHg)

$77 \pm 30$

C.I. $(\mathrm{L} / \mathrm{min} / \mathrm{N}$

$3.7 \pm 2.8$

$53 \pm 24 *$

$5.1 \pm 2.8 *$

Negative Response

$\mathrm{n}=4 ; 10$ to $23 \mathrm{yrs}$ )

Control $\mathrm{PGI}_{2}$

$62 \pm 22 \quad 64 \pm 22$

$1.8 \pm .6 \quad 2.8 \pm 1.1 *$

$41 \pm 33 \quad 26 \pm 16$

Mean $\pm \mathrm{SD} ; *_{\mathrm{p}}<.02 \mathrm{PGI}_{2}$ vs control for each group; PVR=pulmonary vascular resistance.

Patients who had a positive response to $\mathrm{PGI}_{2}$ were found to respond to other vasodilator drugs; non-responders did not respond to other vasodilators. In responders, efficacy of longterm vasodilator therapy remains unknown. The younger children in this series had a greater decrease in PAP with PGI2. We conclude that: 1) a vasodilator response to $\mathrm{PGI}_{2}$ predicts patients likely to respond to subsequent vasodilator therapy, and 2) chitdren with PPH may have a more reactive vascular bed than adults.

\section{O2 TRANSPORT IN CONGENITAL HEART DISEASE}

†81 Wm Berman, Jr. Stephen wood, Steven Yabek and Terrence Dillon. UNM, Alb, NM.

The physiology of oxygen delivery was studied in 83 patients (ages 1d-16yr) at cardiac catheterization. Oxygen consumption $\left(\mathrm{VO}_{2}\right)$, arterial and venous blood gases and oxygen saturations $\left(\mathrm{O}_{2}\right.$ satrange, 41-98\%), hemoglobin concentration (Hb), 2, 3 $D P G$ and $P 50$ levels were measured; cardiac output (CO), systemic oxygen transport (SOT), arterial and venous oxygen contents ([art] and [ven]) and the SOT/VO 2 ratio (l/extraction coefficient) were calculated. $P_{50}$ averaged 32 torr, compared to 28 torr in 8 control children. The composite in vivo $\mathrm{O}_{2}-\mathrm{Hb}$ dissociation curve was broad; $\mathrm{PO}_{2}$ 's varied from 39-60 torr at $80 \%$ O2sat. P50, 2, 3 DPG, $\mathrm{Hb}$ and $\mathrm{O}_{2}$ sat varied widely and inconsistently with $\mathrm{PO}_{2}$, [art] and [ven], but resulted in clustering of [art] near $165 \mathrm{ml} / \mathrm{L}$ ( $\mathrm{SD}+23$ ), over a wide range of $\mathrm{PO}_{2}$ and $\mathrm{Hb}$. SOT varied directly with $\mathrm{CO}(r=0.82 \quad p<.001)$, but not with [art], $\mathrm{PO}_{2}$ or $\mathrm{P}_{50} \mathrm{C}_{\mathrm{T}} \mathrm{VO}_{2}$ varied widely at normal or high levels of sot, but decreased SOT/VO 2 varied inversely with [ven], falling to 2.0 and plateauing below [ven] of $100 \mathrm{ml} / \mathrm{L} ; \mathrm{SOT} / \mathrm{VO}_{2} \mathrm{did}$ not correlate with $\mathrm{PO}_{2}$, [art] or $\mathrm{P}_{50}$. These data suggest $\mathrm{O}_{2}$ sat cannot be predicted accurately from measured $\mathrm{PO}_{2}$, but must be measured directly; 2,3 DPG and P50 fluctuate to stabilize lart]; soT is determined primarily by co and limits $0_{2}$
consumption at low levels of transport; and [ven] is the primary determinant of $\mathrm{O}_{2}$ extraction.
REGIONAL BLOOD FLOW DISTRIBUTION AND OXYGEN DELIVERY 82 IN CHRONICALLY HYPOXEMIC NEWBORN LAMBS. DanieI eymann and $\frac{\text { Bernstein }}{\text { Abraham M. David Teitel, }} \frac{\text { Daniel Sidi, }}{\text { Rudolph. Univ. }} \frac{\text { Michael A. }}{\text { of Calif., Dept. of Peds. }}$ and CVRI, San Francisco.

Redistribution of blood flow is an important response to acute hypoxemia(AH); myocardial and cerebral. flows increase but GI, renal,musculoskeletal and skin flows decrease. It is not known if these changes persist during chronic hypoxemia $(\mathrm{CH})$. We produced $\mathrm{CH}$ in 7 newborn lambs by placing a balloon occluder around the pulmonary artery and performing a balloon atrial septostomy. The 02 sat. was maintained at $60-70 \%$ of control for 2 weeks. Cardiac output $(\mathrm{CO})$ was measured by electromagnetic flowmeter and flow to 9 control lambs, $\mathrm{CH}$ did not alter $\mathrm{CO}$. As with $\mathrm{AH}$, myocardial blood flow increased. Unlike $\mathrm{AH}$, cerebral flow was unchanged from control. Renal, GI tract, musculoskeletal and skin flows decreased, with the percent decreases in flow to the gut and carcreased, with the percent decreases in flow to the gut and car that systemic 02 delivery was normal. However,02 delivery to a11 individual organs was decreased, except to the heart, which showed an increase. Total systemic vascular resistance was unchanged while resistances across each vascular bed changed inversely
related to the changes in flow. Thus regional blood flows are similar during $\mathrm{CH}$ and $\mathrm{AH}$, except for cerebral flow which failed to maintain the increase seen acutely. Although total $\mathrm{CO}$ and 02 delivery may remain normal, decreases in regional 02 delivery may be responsible for. alterations of metabolism and growth in the newborn with cyanotic heart disease.
MAGNETIC RESONANCE IMAGING STUDIES IN COARCTATION

83 OF THE AORTA AND THE MARFAN SYNDROME Robert Boxer, Michael LaCorte, Sharanjeet Singh, Mitche11 Goldman, Harry Stein, Ruben Cooper, Departments of Pediatrics and Radiology, North Shore University Hospital, Downstate, Brook1yn, NY

ECG-gated magnetic resonance imaging (MRI) studies were done on 8 children with coarctation (coarc) of the aorta (Ao), 2-17 yrs., and 8 patients (pts) with Marfan Syndrome (MF), 10-27 yrs. Multiple imaging planes were obtained using a $0.6 \mathrm{~T}$ super-conducting magnet, and $0.75-1 \mathrm{~cm}$ thick sections. In the coarc pts, 1 had MRI pre and post surgery, 1 had MRI pre and post balloon angioplasty (BA), 5 had MRI post BA and 1 had MRI pre BA. Precise visualization of the coarc was noted in the 2 pre therapy studies and in the BA pt the MRI coarc diameter correlated with the angiographic diameter. After therapy there was documentation of relief of the coarc on MRI; no aneuryms were seen in the BA pts. In MF, the Ao root, ascending Ao (Asc Ao), Ao arch and descending Ao (Desc Ao) were well delineated. All MF pts had dilation of the Ao root and Asc Ao: none had dilation of the Desc Ao. In both coarc and MF, the sagittal view gave best visualization of the Ao isthmus, Desc Ao and collaterals when present. Asc Ao and arch vessels were best seen on the left anterior oblique and coronal views. Thus, MRI gives excellent visualization of the Asc Ao, Ao arch, and Desc Ao comparable only to invasive angiography. In coarc, MRI allows accurate localization of si.te of coarc, and non-invasive follow up of treatment. In MF, MRI provides an excellent means of serial evaluation of the aorta.

TNTRAOPERATTVE EVALUATION OF SURGICALLY CREATED

84 SYSTEMIC TO PULMONARY SHUNTS WITH PULSED DOPPLER. Peter A. Ahmann, (Spon. by James F. Schwartz) , Emory University School of Medicine, Department of Pediatrics, Atlanta.

Pulsed Doppler ultrasound (PDU) blood velocity measurements in the carotid artery were compared with outcome of surgically created systemic-to-pulmonary shunts. In 9 shunt cases an $8 \mathrm{MHz}$ PDU probe was placed over the ipsilateral carotid artery and flow velocity was recorded while the shunt was mechanically manipulated from open to closed. The following indices were derived from the velocity waveforms: integrated systolic velocity to integrated diastolic velocity ratio (DV/SV), end diastolic velocity to peak systolic ratio (EDV/PSV), and reverse velocity to forward velocity ratio $(R / F)$. The mean for each index for each patient was less during the shunt open state than the corresponding mean during the shunt closed state. A paired t test for each index showed significance levels of $\mathrm{p}<.01, \mathrm{p}<.001$, and $\mathrm{p}<.025$ for $\mathrm{DV} / \mathrm{SV}$, $\mathrm{EDV} / \mathrm{PSV}$, and $\mathrm{R} / \mathrm{F}$, respectively. The patient with the smallest difference between means of DV/SV and EDV/PSV for the open and closed states required shunt enlargement and the patient with the greatest difference between means required shunt reduction. The remaining 7 shunts were bracketed by these two end points and were deemed adequate at the two week follow-up exam. This preliminary data suggests that PDU velocity derived indices correlate well with shunt magnitude in the acute operative setting. Noninvasive PDU is potentially an inexpensive, convenient, repeatable, and safe alternative to aortography and cardiac catheterization in the assessment of shunt function. 